\title{
Severe Obesity: The Neglected Epidemic
}

\author{
John G. Kral ${ }^{a}$ Ruth A. Kavab Patrick M. Catalano ${ }^{c}$ Barbara J. Moore ${ }^{d}$ \\ ${ }^{a}$ Department of Surgery, SUNY Downstate Medical Center, Brooklyn, NY, b Poughkeepsie, \\ $\mathrm{NY},{ }^{c}$ Case Western Reserve University, MetroHealth Medical Center, Cleveland, $\mathrm{OH},{ }^{\mathrm{d}}$ Shape \\ Up America!, Clyde Park, MT, USA
}

\section{Key Words}

Morbid obesity $\cdot$ Severe obesity $\cdot$ Bariatric surgery $\cdot$ Childhood obesity $\cdot$ Obesity prevention • Women's health $\cdot$ Gestational obesity

\begin{abstract}
Severe obesity (SO) is increasing faster than obesity in adults and in children. Because it is associated with numerous comorbidities, $\mathrm{SO}$ accounts for more health care expenditures than any other medical condition. Furthermore, it is associated with poor pregnancy outcomes for mother, fetus, and infant and a high risk of offspring obesity carried into adulthood. Bariatric surgery is the treatment of choice for SO because nonoperative methods fail to provide medically significant durable weight loss and because it is both preventive and therapeutic. The number of operations has sharply increased globally, yet only a small fraction of eligible patients are referred for surgical treatment demonstrating the need for improved access, especially for those disproportionately affected by SO. The risks of surgery mandate careful postoperative long-term multidisciplinary follow-up care. Education is critical for truly informed consent and must continue postoperatively, especially for women with reproductive potential. Even so, surgical treatment of SO remains cost-effective compared to conventional nonoperative treatment, which also requires long-term care. Just as obesity affects all medical disciplines (from allergology and immunology to oncology, urology and women's health), so does postoperative management of bariatric surgery patients. We offer wide-ranging recommendations for policymakers and others to consider in addressing SO.
\end{abstract}




\section{Introduction}

Obesity (BMI $\geq 30 \mathrm{~kg} / \mathrm{m}^{2}$ ) affects nearly 500 million adults [1] and 40-50 million children globally [2]. Even more alarming is the rapidly growing prevalence of clinically severe obesity (SO) [3] (i.e. BMI $\geq 40 \mathrm{~kg} / \mathrm{m}^{2}$ or BMI $\geq 35 \mathrm{~kg} / \mathrm{m}^{2}$ with manifest serious comorbidity [4]). SO is associated with a high risk of premature death but in aggregate it carries the highest health care costs of any medical condition [5, 6]. SO disproportionately afflicts women as well as minority and low-income populations [7], undermines the reproductive health of women, and raises the risks of birth defects, disease incidence and obesity in offspring $[8,9]$. Health risks and associated costs increase exponentially with increasing BMI in both adults [5, 6] and children [10-12].

Here we discuss the vicious cycle of the growing prevalence of SO among individuals of reproductive potential. Prepregnancy obesity is contributing to a higher prevalence of babies born large-for-gestational-age and to the transmission of obesity from parent to child through non-genetic mechanisms $[13,14]$.

In contrast to their utility in overweight and mild obesity, nonoperative treatments fail to achieve significant durable weight loss or improvement of the metabolic syndrome characterizing SO. Because of the current record of safety and efficacy of bariatric surgery for the treatment of SO, we discuss its emerging role in improving the reproductive health of women and stemming the propagation of obesity from parent to child.

Bariatric surgery requires a relatively high initial investment in education, staff, training, and equipment. It is often not covered by health insurance and is thus neither accessible nor affordable for the low-income and minority populations in which SO is most prevalent. In spite of demonstrable benefits, it has risks and side effects requiring long-term monitoring and supplementation, especially in women who may become pregnant.

We suggest a broad range of initiatives to improve education about the chronic overnutrition syndrome of SO and effective treatment of this increasingly prevalent disease. To stem intergenerational transmission of obesity, there is an urgent need to i) prevent obesity and SO in people with reproductive potential, ii) prevent pregnancy in those already obese and severely obese, and iii) effectively treat people currently afflicted with SO to minimize the risks of gestational obesity and optimize healthy outcomes for mother and offspring. If Society is willing to prosecute drug-abusing mothers and warn of alcohol and tobacco use during pregnancy, should we not be serious about preventing obese pregnancies? We present a rationale for needed changes in education, clinical practice, and public policy to achieve these overarching goals.

\section{Scope and Impact}

Regardless of how it is defined, SO prevalence appears to be increasing more rapidly than mild or moderate obesity in the developed countries in which it is documented $[6,15$, 16]. Measured data (fig. 1) illustrates the rapid increase of SO compared to less severe forms of adult obesity:

These trends in measured data agree with self-reported data reported by Sturm [15]. Data on SO trends in other countries are scant, but suggest a similar pattern. In Sweden, young adult men exhibited a 5 -fold increase in moderate obesity over the 30-year period ending in 2005, whereas SO increased 10 -fold [16] and is projected to affect $4 \%$ of the adult Swedish population by 2020 [16]. In Australia, SO increased 4.5-fold between 1991 and 2006 with highest levels in women and the poor [17]. The Health Survey for England showed that adult SO doubled in the 13 years from 1995 to 2008 with higher levels for women [18]. 
Fig. 1. Percent increase in adult severe (BMI of 40 and $45 \mathrm{~kg} / \mathrm{m}^{2}$ ) and moderate (BMI of $35 \mathrm{~kg} / \mathrm{m}^{2}$ ) obesity compared to simple obesity (BMI of $30 \mathrm{~kg} / \mathrm{m}^{2}$ ) or overweight (BMI of $25 \mathrm{~kg} / \mathrm{m}^{2}$ ), using 1960-1962 data as baseline (data source: NHES and NHANES data as reported by Ruhm [81]. In adults, the most severe forms of obesity (classes II (BMI $35 \mathrm{~kg}$ / $\mathrm{m}^{2}$ ), III (BMI $40 \mathrm{~kg} / \mathrm{m}^{2}$ ) and IV (BMI $45 \mathrm{~kg} / \mathrm{m}^{2}$ ) are increasing more rapidly than either overweight (BMI $25 \mathrm{~kg} / \mathrm{m}^{2}$ ) or Class I (BMI $30 \mathrm{~kg} / \mathrm{m}^{2}$ ) obesity.

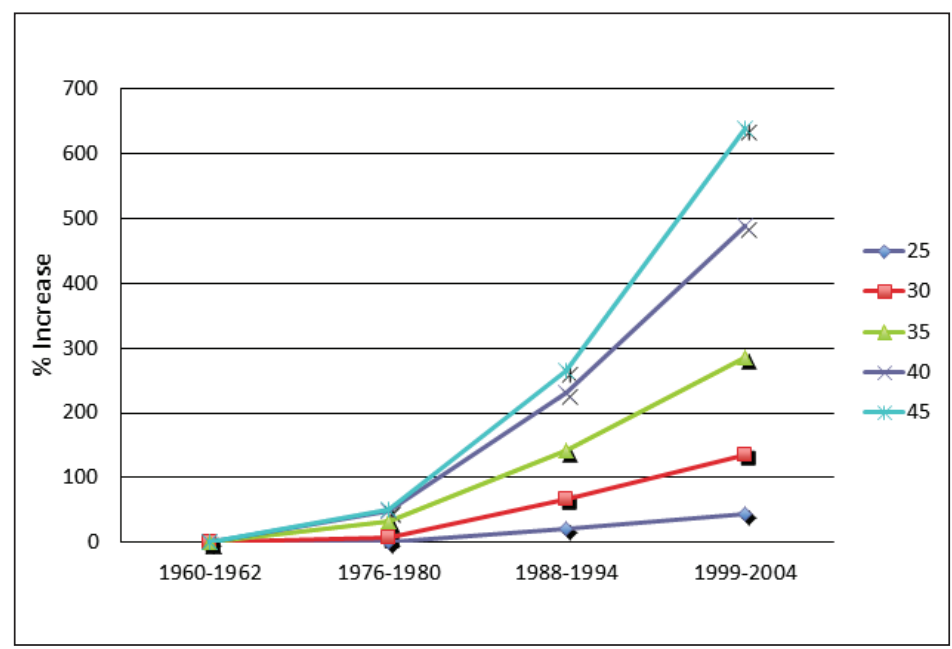

Of particular concern for reproductive health is that models predict a tripling of SO prevalence for English women by 2030 [6]. In the USA, SO prevalence (BMI $\geq 40 \mathrm{~kg} / \mathrm{m}^{2}$ ) is already $7.5 \%$ in women in their prime reproductive years (ages $20-39$ years) and $17.2 \%$ for BMI $\geq 35 \mathrm{~kg} / \mathrm{m}^{2}$ [7]. One quarter of American black men and women of reproductive age has $\mathrm{BMI} \geq 35 \mathrm{~kg} / \mathrm{m}^{2}[7]$.

Obesity prevalence in children appears to be increasing globally [19]. Regardless of definition, pediatric SO is increasing in the USA, especially among minority and lower income children [20]. SO prevalence quadrupled since the late 1970s among all US children (ages 2-19 years), and reached 4.9\% for the period 1999-2006; among teens it is 5.6\% [20], which is of particular concern because of their developing reproductive potential. There are marked differences in SO prevalence among teens based on sex, race/ethnicity, and socioeconomic status: prevalence was $12.6 \%$ among Blacks and $6.3 \%$ among Hispanics compared to $4.8 \%$ in whites [20]. Girls from lower income (defined as a poverty index ratio of $<130 \%$, reflecting eligibility for federal food assistance programs) families were more likely than boys to be classified as SO (odds ratio 1.51 (1.14-2.00) [20].

To put these data into clinical perspective: SO teenage girls and boys carry an average 25 and $29 \mathrm{~kg}$ of excess weight, respectively [20].

\section{Impact on Health}

Obesity or chronic overnutrition - routine ingestion of calories in excess of physiological need - is associated with a host of metabolic derangements and increased risk for diseases and disability (table 1).

As BMI increases, the number and severity of metabolic derangements increase in adults $[1,6]$ and children $[10,11]$. The impact on reproductive health is of particular concern because of the association between maternal prepregnancy obesity with serious pregnancy complications, greater fetal adiposity, and the development of childhood obesity in the offspring (table 2).

\section{Impact on Reproductive Health and Intergenerational Transmission of Obesity}

Although such data from other countries are scant, US data suggest that SO is increasing in reproductive-age women [21]. Among 20- to 39-year-old US women prevalence is high (6.9\%), and even higher in Blacks (14.7\%) [7]. Among American Indian and Alaskan Native 
Table 1. Risks of SO and benefits of obesity surgery

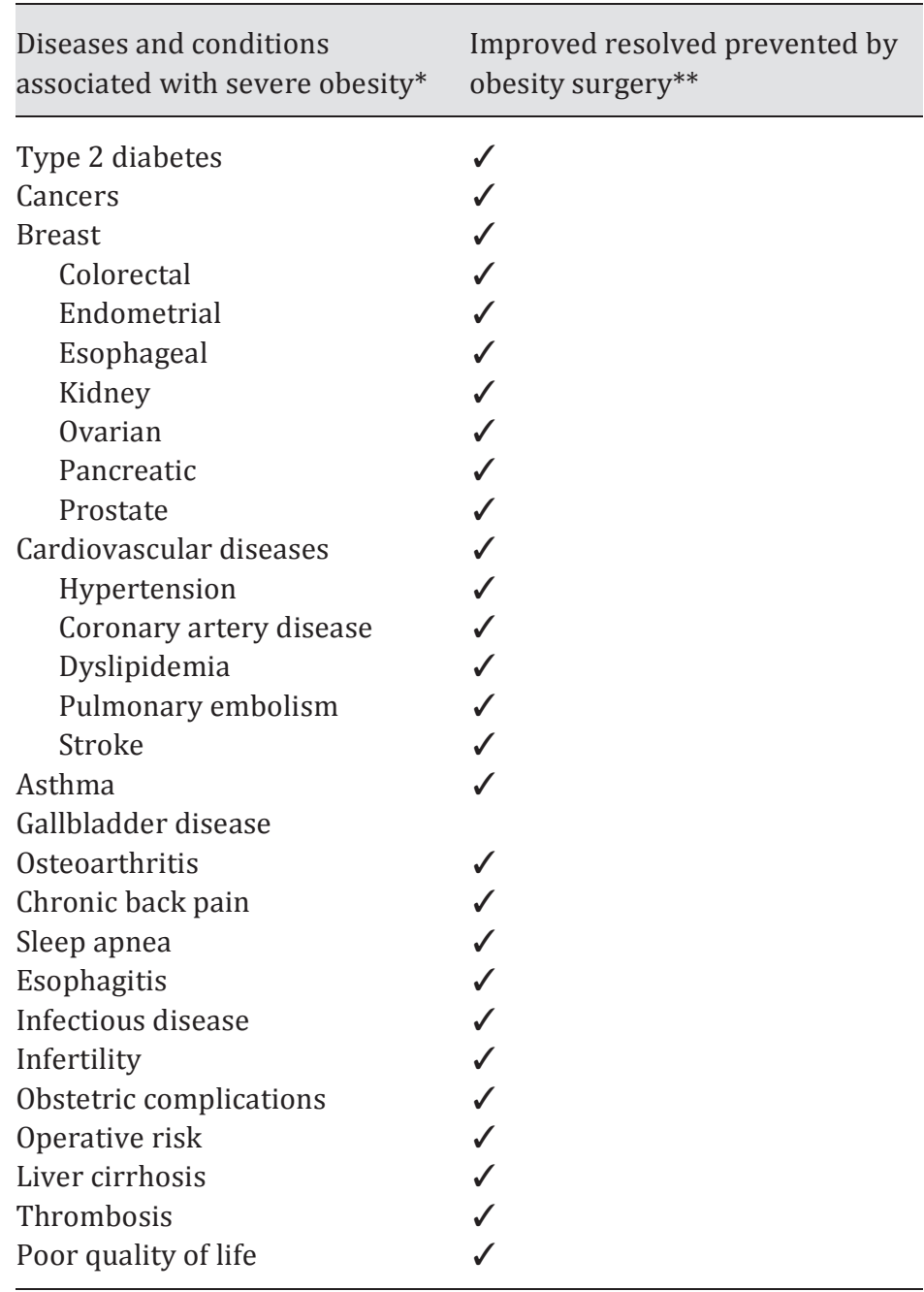

*Adapted from data extracted from 89 US and European studies as reported in Guh et al. [82].

**Adapted from Kral [83].

adults with diabetes, SO is more prevalent among women; by 2004 it was an astounding $37 \%$ among adults 18-39 years old [22]. If they carry to term, SO women are more likely to have fatter babies [23], who are more likely to be obese by the age of 4 [24] and remain so through adolescence and into their reproductive years [11,25].

In one study from the UK, parental obesity was one of the strongest risk factors for childhood obesity: the higher the parental BMI, the greater the risk [14]. In the USA, studies by Catalano et al. [23] and Boney et al. [26] showed that maternal pregravid BMI was a strong predictor of childhood obesity and its comorbidities in the offspring. Hence, the global escalation of juvenile SO prevalence threatens to predispose future generations of children to obesity as these young people reach reproductive age [25, 26].

Data from the Health Surveys for England (HSE) 2001-2006 on 4,423 English families with 7,078 children (biological offspring) aged 2-15 years illustrates the impact of parental obesity on offspring obesity [14] (fig. 2). 
Table 2. Pregnancy complications of SO

\author{
Maternal \\ Gestational diabetes mellitus (GDM) \\ Pre-eclampsia \\ Eclampsia \\ Gestational hypertension \\ Pseudotumor cerebri \\ Acute cholecystitis \\ Cesarean section \\ Postpartum wound infections \\ Operative vaginal delivery \\ Metabolic disturbances \\ Elevated free fatty acids \\ Hyperglycemia
}

\title{
Fetal/Neonatal
}

Spontaneous abortion

Stillbirth

Fetal monitoring and imaging problems

Premature birth secondary to obstetrical and medical complications

Intrauterine growth restriction (IUGR), secondary to problems such as preeclampsia

Congenital malformations

Low Apgar score

Large for gestational age (LGA)

Increased fetal adiposity

Hypoglycemia

\author{
Neonatal/Infant/Child \\ Difficulty breastfeeding \\ Risk of low IQ \\ Aggressive eating style \\ Risk of pediatric obesity \\ Type 2 diabetes \\ Metabolic syndrome \\ Impaired glucose tolerance \\ Dyslipidemia \\ Hypertension \\ Fatty liver disease \\ Asthma \\ Depression \\ Orthopedic disorders \\ Truancy
}

Offspring obesity prevalence with 2 normal-weight parents was $2.3 \%$ versus $4.9 \%$ with 2 overweight parents; it increased to 21.7\% among offspring of 2 obese parents, and to a remarkable $35.3 \%$ with 2 SO parents (fig. 2). These effects were similar in sons and daughters and in younger and older children [14].

The intergenerational transmission of obesity is stronger for maternal than paternal obesity (fig. 2) [14]), implying an important role of the uterine environment. A large body of epidemiological evidence supports the field of Developmental Origins of Adult Disease (DOAD), recently linked to epigenetic mechanisms of intergenerational transmission [27]. 


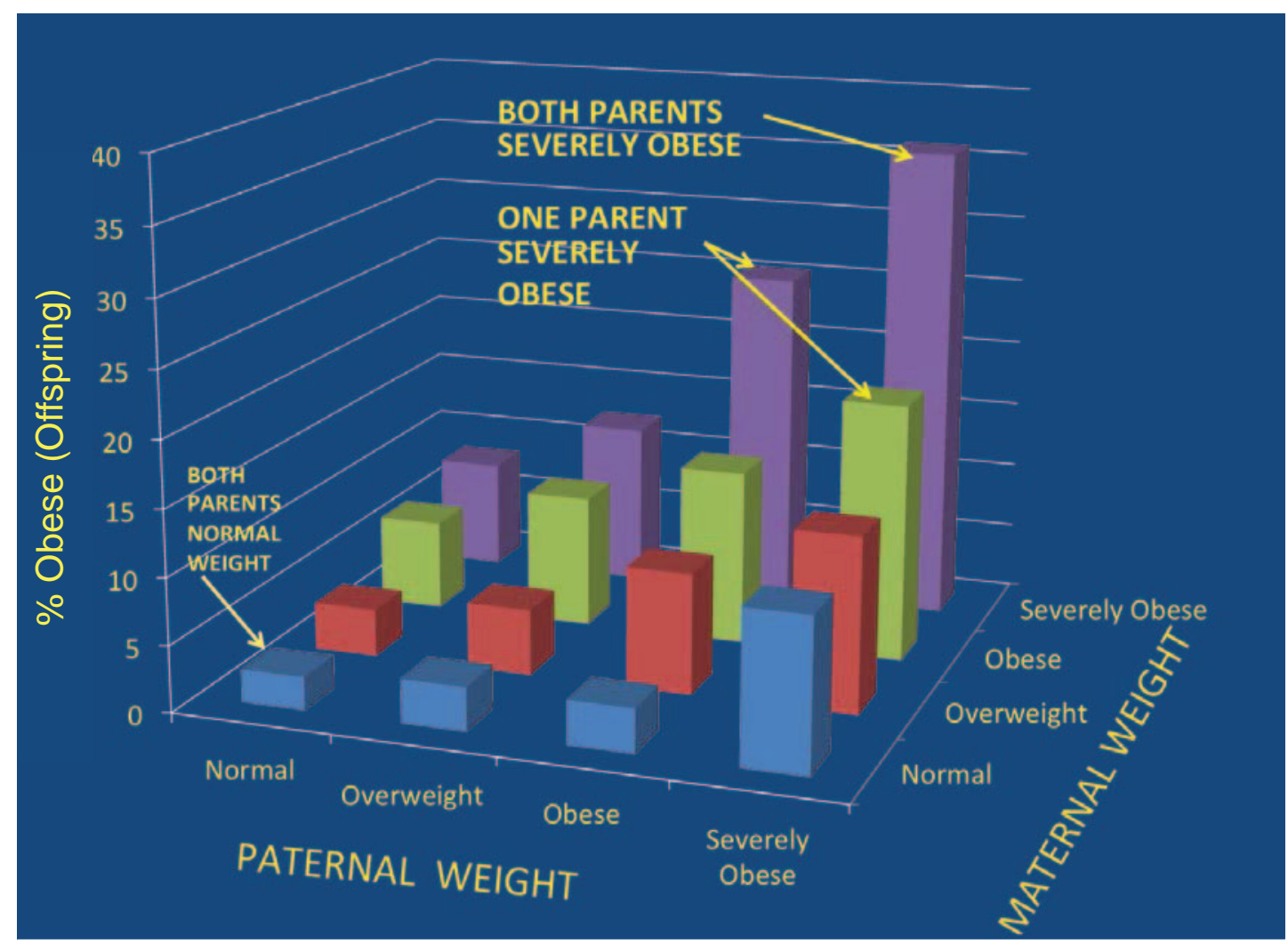

Fig. 2. Intergenerational transmission of obesity to offspring based on parental weight status (data source Whitaker et al. [14]). The impact of parental weight status on childhood obesity is graded. The risk is lowest when both parents are normal weight but risk increases more than 20 -fold when both parents are severely obese.

These are responsible for metabolic imprinting on developing susceptible neural circuits during gestation and infancy, demonstrated in rodents $[28,29]$ as well as non-human primates [30]. The data suggest that parental obesity, by whatever mechanism(s), predisposes the offspring to obesity.

To insure a healthy pregnancy, Canadian guidelines call for women to enter pregnancy with a BMI $<30$ and ideally $<25 \mathrm{~kg} / \mathrm{m}^{2}$ [31]. The Institute of Medicine recommends that obese (including SO) women gain no more than 5-9 kg (11-20 lbs) during the course of pregnancy. The dissonance between these guidelines and the prevailing trends in prepregnancy obesity [21,22] and the $40-60 \%$ excessive gestational weight gain typical of overweight and obese pregnancies [13] has serious negative consequences for future generations.

\section{Severe Obesity: Economic Impact}

Because of the large number of comorbidities and earlier age of onset, the rapid increase in SO contributes significantly to escalating health care costs; yet few analyses distinguish between costs attributable to SO versus overweight and/or obesity. Between 1987 and 2007 the difference in US health care spending between obese and normal-weight adults increased from 8 to 38\% [32]. Health care costs of obesity are predicted to increase, accounting for an increasing share of total US and UK health care spending [1]. In England, one analysis of the National Health Service (NHS) expenditures found that the direct costs of obesity and related illness amounts to $5 \%$ of the NHS budget [33]. 
The costs of obesity-related health care for self-insured employers - in both direct and indirect expenditures - correlate with the degree of obesity: annual direct costs are 3 times higher for SO workers than for obese workers and more than 10 times higher than for overweight employees [34]. Indirect costs of obesity may exceed the direct medical costs. Finkelstein et al. [35] reported higher rates of lost productivity due to both absenteeism and presenteeism among SO employees in the USA, absenteeism amounting to 5.9 more days/ year in SO men as compared to men of healthy weight. 'Presenteeism' is a term capturing reduced productivity on the job that Finkelstein et al. [35] estimated in the American SO workforce as equivalent to 1 month of lost productivity per year.

We found no economic analyses of costs associated with the growing prevalence of SO in persons of reproductive potential or with the intergenerational transmission of obesity, although obesity significantly increases costs and charges of hospitalization during pregnancy [36]. Systematic documentation of such costs is a pressing research need.

\section{Surgical Treatment of Severe Obesity}

Although overweight and obesity are responsive to non-operative treatment over the short term, this is not the case for $\mathrm{SO}$, a fact that stimulated the development of anti-obesity ('bariatric') surgery. Obesity surgery has existed for 60 years, starting with small bowel resections succeeded by gastrointestinal bypass and gastric restrictive (banding) operations. The bariatric procedures are physiologically similar to common operations in general surgical practice with well-characterized perioperative and long-term complications and side effects, with knowledge accumulated over more than a century. Nevertheless, bariatric surgery is like no other gastrointestinal surgery owing to its substantial effects on eating behavior [37].

It is not our purpose to review the field of bariatric surgery but understanding the following points is necessary to support and justify our policy recommendations. There are two mechanistically different generic types of operations, with substantial differences in perioperative, early, and long-term outcomes. Indiscriminate use of the term 'bariatric surgery' without distinguishing between the two types causes unnecessary controversy and confusion in the fields of public health, nutrition, and obesity.

Laparoscopic adjustable banding: Placing an inflatable circumgastric band around the uppermost portion of the stomach restricts the amount and emptying time of solid food. It requires frequent office visits for band adjustments and intensive pre- and postoperative education to optimize outcomes, reinforcing rules of eating and 'rules of vomiting' [38, 39] to avoid complications and re-operations. Calorie-containing liquids (e.g. ice cream) or soft solids (e.g. chips and snacks that readily become liquid in the mouth) can pass through the band and defeat this procedure by limiting weight loss or causing weight regain [40].

Laparoscopic gastric bypass (termed Roux-en Y gastric bypass (RYGB)) is a diversionary (or 'bypass') operation that creates a transiently restrictive gastric pouch that empties directly into a loop of distal small intestine, thus bypassing $>90 \%$ of the stomach, the pylorus, duodenum and first portion of the jejunum. Bypass operations such as RYGB and the more complex biliopancreatic diversion (BPD), which removes part of the stomach and excludes the duodenum and jejunum from nutrient flow, have beneficial metabolic effects. The latter are due to the altered digestion and rate and path of flow of nutrients affecting the release of neuroendocrine 'satiety' peptides [38, 41].

Compounding confusion is the continued innovative development of operations while discarding others, lack of standardization of operations bearing the same name, and researchers' eagerness to publicize premature findings. 
Banding and bypass can be performed via two different approaches: open, with large incisions prone to complications, and laparoscopic, with small, minimally invasive puncture wounds, the latter becoming the standard of care around 2003. The two approaches have very different outcomes affecting risks, costs, and benefits. Laparoscopic approaches have revolutionized all surgery by shortening hospital stay and hastening return to full activities of daily living and reducing wound complications such as infections, bleeding, and hernia, this last being of great importance for the susceptible SO patient population. The major complication rate following open gastric bypass is approximately 10 times greater than that of laparoscopic gastric bypass [42].

The time courses of risks and benefits of banding and bypass differ, requiring different periods of close observation postoperatively to document and compare weight loss and metabolic outcomes. Failure to differentiate procedures distorts interpretations. The rapid weight loss phase after banding lasts approximately 9-12 months, after bypass 12-18 months. Weight loss nadir as well as weight regain have different trajectories for the two classes of operations. Thus, physiological, clinical, or economic cost studies performed prior to weight stability (steady state conditions) are unreliable.

Obese people differ in their responses to the different operations, placing the onus on the surgeon to provide thorough preoperative education to enable patients to choose (if real choices are available) between procedures. Such education is obligatory for truly informed consent. Regardless of known predictors of complications and mortality and even with significant high quality pre-operative education, patients must be free to make independent choices whether or not they are the safest from a medical point of view, a quandary in all medical care.

It is neither scientifically nor ethically defensible to randomize patients between operations such as banding or bypass with disparate effects and outcomes, or between any surgical and non-surgical treatment without violating equipoise and patients' rights to selfdetermination [43]. Using the established criteria of evidence-based medicine (EBM) requiring prospective randomized controlled studies to achieve higher 'levels of evidence', the preponderance of studies of bariatric surgery have been systematically and unjustifiably excluded from authoritative reviews and meta-analyses of risk-benefit ratios [44]. This contributes to third-party payers' refusal to cover this life-saving treatment.

Clear definition of appropriate criteria for SO, 'successful' weight loss, access to care, reimbursement, eligibility for treatments, coverage policies, and participation in clinical trials is urgently needed. Because BMI is highly correlated with body fat, it is useful for assessing population health, yet neither BMI nor body fat are suitable markers of 'metabolic obesity' - the chronic inflammatory insulin-resistant overnutrition syndrome that requires medical attention $[4,45]$. For example, a Caucasian with BMI $=22 \mathrm{~kg} / \mathrm{m}^{2}$ with increased volume of visceral fat is more likely to have insulin resistance than one with BMI $=30 \mathrm{~kg} /$ $\mathrm{m}^{2}$ with peripheral or distal distribution of fat. To our point, BMI is an unreliable indicator of medically significant weight loss. A patient operated at a BMI of $46 \mathrm{~kg} / \mathrm{m}^{2}$, who reduces to BMI of $35 \mathrm{~kg} / \mathrm{m}^{2}$, is categorized as 'obese', and thus a failure of bariatric surgery, despite amelioration of insulin resistance, dyslipidemia or other markers of metabolic syndrome. This patient should not be compared to an untreated patient with BMI $=35 \mathrm{~kg} / \mathrm{m}^{2}$ [37]. This common misclassification error denigrates the clinical achievement and thus the value of bariatric surgery. Consequently, alternative measures are being considered $[45,46]$.

\section{Benefits of Bariatric Surgery}

Obesity surgery exchanges the progressively debilitating intractable comorbidities of SO for the side effects and complications of operations designed to create chronic undernutrition. Sustained medically significant weight loss after bariatric operations affecting metabolic and physical obesity ameliorates or cures the numerous serious comorbidities of 
SO, positively affecting health and quality of life $[47,48]$. These benefits (table 1 ) include significant reductions in cancer incidence $[49,50]$, cardiovascular events [51], and all-cause mortality [52, 53].

Bariatric operations are preventive as well as therapeutic. Surgical weight loss can forestall or halt development of a large number of comorbidities (table 1). Important from a cost perspective, bariatric surgery improves outcomes and sometimes obviates the need for other major operations such as kidney, heart and liver transplantation, hip replacement, and cancer surgery. Earlier intervention in any disease process provides greater likelihood of achieving partial or total remission, an argument for performing bariatric surgery at younger ages and lower BMI than current practice standards. Indeed, trends since 2000 demonstrate that increased numbers of patients with BMI $30-35 \mathrm{~kg} / \mathrm{m}^{2}$ and of adolescents are being operated.

Remarkably, bariatric surgery in obese young women with reproductive capacity, constituting $50 \%$ of operated patients, offers clear therapeutic and primary preventive benefits [54,55]. It improves fertility, reducing the need for pharmacologic treatment and in vitro fertilization, and is beneficial for maternal-fetal health and survival including reduced complications of labor and delivery.

There is evidence from the U Laval Mother-Child Obesity Study in Quebec that significant sustained weight loss in SO women after bariatric surgery and prior to conception achieves healthier pregnancies with less gestational weight gain, fewer complications at delivery, and a greater than $50 \%$ decreased risk of offspring obesity [56]. Studies of surgical weight loss compare offspring born to mothers prior to surgery with those born to the same mothers after surgery [56-58]. After controlling for offspring age, the prevalence of childhood and adolescent SO in the Quebec study was reduced from 35 to $11 \%$ in those born after the surgery; decreased maternal SO was also associated with significantly improved lipid profiles and insulin sensitivity in the offspring [57]. The salutary effects of preconception weight loss and reduced gestational weight gain are evident in recent studies regardless of postsurgical timing of conception [57, 59, 60], although generally surgeons have advised against pregnancies within 18-24 months postoperatively.

\section{Bariatric Surgery Risks}

Bariatric surgery has attendant risks, including death (table 3); risks of any surgery are greater in obese people [61]. Gastric restrictive procedures, especially banding, are associated with vomiting (which, when excessive, can lead to iron, thiamine and other deficiencies requiring assiduous supplementation) as well as mechanically induced band problems and pouch stretching with weight regain, requiring reoperation. Patients with bypass operations are also prone to deficiencies unless they adhere to routinely recommended supplements with vitamins and minerals. Vigilant monitoring of nutritional status in women of reproductive capacity is imperative. Bypass operations may interfere with absorption of medications, including oral contraceptives and other hormones, thus requiring dose adjustments.

When reviewing population-level statistics as well as controlled trials or case series describing complications, side effects, and mortality after bariatric surgery, the data reveal that reproductive-age women have the lowest complication rates for 3 reasons: i) they are younger, (older age is a risk factor for poor outcome), ii) in aggregate they are in the lowest range of BMI (35-45 kg/m $\left.{ }^{2}\right)$ with the lowest complication and mortality rates (high BMI being another risk factor), and iii) women generally have lower complication and mortality rates than men $[62,63]$. Nevertheless, depending on type of operation and the quality of follow-up care, there are risks and complications that are especially serious for women with reproductive capacity. 
Table 3. Adverse effects of obesity surgery

\begin{tabular}{l} 
Perioperative \\
Thromboembolism \\
Bleeding \\
Pneumonia \\
Stenosis \\
Ulcers \\
Infection \\
Hernia \\
Peritonitis \\
Death $\sim 0.3 \%$ \\
\hline Long-term effects \\
Deficiencies \\
$\quad$ Iron \\
$\quad$ Calcium, vitamin D \\
$\quad$ Vitamin B12 \\
$\quad$ Protein \\
Gallstones \\
Weight regain \\
Reoperation \\
\hline
\end{tabular}

Two comprehensive reviews conclude that bariatric surgery improves maternal and neonatal outcomes $[54,64]$. While case reports of adverse outcomes include death, malformations, herniae and serious deficiencies $[65,66]$, most are owing to vitamin and mineral deficiencies attributed to non-adherence to vitamin supplementation and failure of postoperative monitoring. This emphasizes the continuous need for pre- and postoperative education.

Nonetheless, reproductive-age women are in the lowest risk group for adverse outcomes of bariatric surgery.

\section{Cost-Effectiveness of Bariatric Surgery}

Although relatively expensive in the short term, bariatric operations cost less than hip or knee replacement, cardiovascular surgery, organ transplantation, and cancer surgery, all of which can be prevented by prior bariatric surgery [62]. Cost-effectiveness analyses are hampered by heterogeneous sources of expenses and savings, variable accounting methods, and the absence of objective measures of quality of life and patient satisfaction, the ultimate moral arbiters of outcomes of medical care.

Despite this variability, analyses have uniformly demonstrated that bariatric surgery is cost-effective compared to regular care (diet and intensive lifestyle intervention with or without pharmacotherapy) for treating SO. On a cost-per-kg-lost basis, break-even occurs in as little as 1 year [33] and a return on investment (ROI) after as little as 2-4 years, depending on method of calculation, type of operation, and the volume and competence of the bariatric surgery center $[6,67]$.

The English NHS analysis mentioned earlier suggested that if just $5 \%$ of eligible patients were to have bariatric surgery the net savings over 3 years would be nearly GBP 400 million [33]. These savings would more than triple if $25 \%$ of eligible SO patients were surgically treated [33]. That estimate does not include additional economic benefits associated with decreased absenteeism and increased worker productivity [33].We found one study reporting higher costs (compared to costs of standard treatment) associated with a lifestyle 
change intervention designed to curtail gestational weight gain (GWG) in obese gestation [68], but no cost-effectiveness studies analyzing the ability of bariatric surgery to reduce costs associated with any aspect of gestational obesity including excessive GWG. This is a research need since obese pregnancies typically involve high GWG and are known to be many times more costly than normal-weight pregnancies [36]. Similarly there are no costeffectiveness studies taking into account the perinatal medical and lifetime costs of offspring born before versus those born after maternal bariatric surgery, nor long-term studies comparing costs over the life cycle.

\section{Policy Issues - Access to Care}

In the 1980s and 1990s differences in outcomes related to socioeconomic factors, commonly using insurance status as a surrogate, were recognized $[69,70]$. Such disparities in treatment outcomes are similar across most medical specialties adjusted for race and education yet rarely for disease severity. Yet this is often the case for SO patients without access to care or sufficient education to recognize symptoms of disease or seek available medical care. One study found that SO Medicaid patients were younger but much heavier $\left(\right.$ mean BMI $=58 \mathrm{~kg} / \mathrm{m}^{2}$ ) with more comorbidities than Medicare (mean BMI $=53 \mathrm{~kg} / \mathrm{m}^{2}$ ) or commercial/self-pay patients (mean BMI $=51 \mathrm{~kg} / \mathrm{m}^{2}$ ), indicating more advanced disease at the time of surgery [71]. Yet outcomes were similar when the data were adjusted for these baseline differences [71].

With respect to women with reproductive potential, one US study covering 26 of 50 states showed that obesity was the most prevalent medical condition in women who had reproduced at least once, followed by overweight, underweight, anemia, asthma, hypertension, and diabetes [72]. Obesity prevalence was higher in minority women and those of lower socioeconomic status and was highest (mean: $26.7 \%$ ) in women whose most recent delivery was an unintended pregnancy and women with Medicaid coverage (mean 32.7\%). The authors suggested that their data should be used to target women with poorer preconception and interpregnancy health who would benefit the most from targeted public health interventions. The prevalence of obesity among women who reported smoking during pregnancy increased from about 1 in 10 in 1993-1994 to 1 in 5 in 2002-2003 [21]. Clearly, the need to address unhealthy behaviors affecting pregnancy outcomes has never been greater. To improve pregnancy outcomes in SO women, obstetricians and gynecologists should alert reproductive age SO women to the need for pre-conception weight loss and limited GWG after conception and, when appropriate, to consider referral to bariatric surgical centers. But none of this can happen without access to medical care for minority and low-income SO populations.

In the USA there are clear socioeconomic disparities between those who do or do not undergo bariatric surgery, despite medical eligibility [73]. Even in countries with publicly funded universally accessible health care this is a problem. One study from Canada suggested that eligible persons of lower income status were less likely to be approved for bariatric surgery [74].

Although there are numerous predictors of poor outcomes after bariatric operations, results are superior to those of non-surgical methods. Withholding bariatric surgery for conditions such as drug and alcohol abuse, poor cooperation, mental illness including cognitive impairment, low socioeconomic status, genetic abnormalities etc. is not congruent with current values in a humane society. It is beyond the scope of this text to adjudicate controversies over the eligibility of uneducated, cognitively impaired subjects, but civilized nations provide surgical treatment by appointing health care surrogates to safeguard the consent process for minors and the mentally impaired. 


\section{Existing Policies on Severe Obesity Treatment}

In the USA in 1991, with $<3 \%$ of the SO population (BMI $\geq 40 \mathrm{~kg} / \mathrm{m}^{2}$ ) [75], the National Institutes of Health (NIH) held a consensus conference endorsing bariatric surgery in persons with BMI $\geq 40$ or $35-40 \mathrm{~kg} / \mathrm{m}^{2}$ with significant comorbidities [76]. This was codified in the first set of comprehensive guidelines for the treatment of adult obesity published by the NIH in 1998 [77] by which time SO prevalence was approaching 5\% [75]. Today, with the overall prevalence of SO above 6\% [7], and at a record $7.5 \%$ in women of reproductive age [7], those guidelines are under review: new ones are expected to be available for public comment late in 2012. Clearly, efforts to prevent and treat SO have been inadequate, and new strategies are urgently needed to improve access to care.

The existence of publicly funded health care does not guarantee access to care. In England, with an estimated 2\% of the adult population being severely obese in 2006, the NHS National Institute for Health and Clinical Excellence (NICE) issued a set of guidelines very similar to those issued in the USA with respect to the use of bariatric surgery for the treatment of SO [33]. Yet a 2010 survey of Primary Care Trusts (PCTs) in England concluded that adherence to the NICE guideline is 'inconsistent and sub-optimal' [33] citing the extremely low number of bariatric procedures performed in 2009-2010. Despite evidence that significant cost savings to the NHS would be realized through wider utilization of bariatric surgery for appropriate candidates, 1 out of 3 PCTs reported that they would be even less likely to use bariatric surgery in the future; several reported using criteria of their own, and several cited budgetary constraints as a barrier [33].

Also in 2006, the US Centers for Medicare and Medicaid Services (CMS) established a national coverage policy for weight loss surgery for SO and in 2009 further specified that type 2 diabetes be considered in determining coverage of SO Medicare beneficiaries [78, 79]. Many Medicaid programs now offer weight loss surgery for the poor, just as the Medicare program does for seniors and the disabled, but approval of surgery is often delayed [71] and coverage varies markedly by region [80] as it does in the UK [33].

\section{Recommended Policy Initiatives}

Policy changes at government levels ranging from local to national can remove barriers to treatment and improve standards of care. We are calling for the support and active participation of all stakeholders, whether health practitioners in the field, educators, journalists, workers in related industries (insurance, hospital, food, entertainment etc.), professional societies, employers or government policymakers, to consider implementation of the recommendations presented below along with a brief rationale for each (table 4).

\section{Conclusion}

Because comorbidities and health service utilization and costs are higher among SO individuals, the escalating prevalence of this condition has profound economic consequences $[1,5]$. Surgical treatment of SO is both clinically effective and cost-effective and pays for itself in 1-4 years. The capacity of surgical treatment of SO to stem intergenerational transmission of obesity, reduce pregnancy complications, and improve maternal and fetal outcomes represents an essential benefit of this treatment that stands to help stem the epidemic. Because SO is more prevalent among minority and lower socioeconomic status groups who face barriers impeding access to all medical care, identifying and removing barriers to surgical treatment for people with reproductive potential among these groups is an urgent public health priority. 
Table 4. Recommendations and rationale

Recommendation

1 Charge the International Obesity Task Force (IOTF) with establishing definitions of severe obesity in adults and children suitable for international use.

2 Incorporate multi-disciplinary assessment using metabolic markers and comprehensive treatment plans (including bariatric surgery) for severe obesity into all medical practice guidelines, especially in Obstetrics and Gynecology.

3 Require government and other health insurers (3rd party payers) to include assessment and treatment of severe obesity as standard benefits.
Rationale

Appropriate definitions permit comparison of data within and among countries and facilitate identification of useful strategies to stem or slow obesity.

Ensures standardized assessment and referral of severely obese patients at the same time establishing standards for documenting long-term safety and effectiveness of bariatric surgery.

Decreases disparities among low-income populations disproportionately afflicted by severe obesity; removes insurance barriers to treatment.

4 Mandate and fund education about obesity comorbidity Increases awareness among medical practitioners of the health including complications of gestational obesity and poor risks of severe obesity and their impact on women's health and maternal, fetal and infant health outcomes as part of the reproduction; helps stem parent-child transmission of obesity. core training of students and practitioners.

5 Develop comprehensive curricula for pre- and postop- Increases knowledge of differential effects of bariatric operaerative patient education enabling informed consent for tions on required changes in eating behavior and activities of generically different bariatric operations; identify evi- daily living and the need for cooperation with treatment plans; dence-based consensus-driven web resources for clini- enhances quality of care and respects patients' rights to selfcians and patients. determination.

6 Define the composition and qualifications of multidisci- Provides equitable services, standardization of treatment and plinary teams participating in the comprehensive lifelong management, including education and treatment, improved outcomes. Facilitates research and development of treatment and prevention. of severely obese patients as a pre-requisite for reimbursement of services.

7 Create funding mechanisms to increase access to and Targets the low-income populations who are disproportionateaffordability of all medical care as a priority for severe- ly affected by severe obesity and greatly contribute to costs of ly obese reproductive age individuals. the burgeoning epidemic.

8 Educate employers and worksites of the costeffectiveness of bariatric surgery and the economic benefits of treating severe obesity.

9 Enhance health education curricula to teach principles of healthy weight management and the hazards of obesity and its role in jeopardizing the health of future generations; call upon school nurses to identify overweight and obese students and to recommend trusted referral resources to parents/caregivers.
Increases awareness that such treatment provides a return on investment within 2-4 years and increases worker productivity by reducing absenteeism and presenteeism.

Addresses a critical pervasive need for Increased knowledge and awareness of the health risks of severe obesity, including its impact on women's health and offspring obesity; helps stem parent-child transmission of obesity. 
Kral et al.: Severe Obesity: The Neglected Epidemic

\section{Disclosure Statement}

Drs. Kava, Kral and Catalano have no conflict of interest to report. Dr. Moore is an unpaid volunteer serving as president and CEO of Shape Up America! - a US nonprofit educational organization - that has received the majority of its funding from the weight loss industry, the food industry, the pharmaceutical industry, the bariatric surgical device industry and an electronic body composition measurement company.

\section{References}

1 Wang YC, McPherson K, Marsh T, Gortmaker SL, Brown M: Health and economic burden of the projected obesity trends in the USA and the UK (Obesity 2). Lancet 2011;378:815-825.

2 International Obesity Taskforce (IOTF): The Global Epidemic. Available at www.iaso.org/iotf/obesity/obesitytheglobalepidemic/ (last accessed January 26, 2012).

3 National Center for Health Statistics NCHS Health E-Stat: Prevalence of Overweight, Obesity and Extreme Obesity among Adults: United States, Trends 1976-80 through 2005-2006. Available at www.cdc.gov/nchs/ fastats/overwt.htm (last accessed January 26, 2012).

- 4 Kral JG: Morbidity of severe obesity. Surg Clin North Am 2001;81:1039-1061.

5 Hensrud DD, Klein S: Extreme obesity: a new medical crisis in the United States. Mayo Clin Proc 2006;81(10 suppl):S5-S10.

6 Picot J, Jones J, Colquitt JL, Gospodarevskaya E, Loveman E, Baxter L, Clegg AJ: The clinical effectiveness and cost-effectiveness of bariatric (weight loss) surgery for obesity: a systematic review and economic evaluation. Health Technol Assess (Winchester) 2009;13(41):1-190.

7 Flegal KM, Carroll MD, Kit BK, Ogden CL: Prevalence of obesity and trends in the distribution of body mass index among US adults, 1999-2010. JAMA 2012;307:491-497.

- 8 Kral JG: Preventing and treating obesity in girls and young women to curb the epidemic. Obes Res 2004;12: 1539-1546.

- 9 Catalano PM: Management of obesity in pregnancy. Obstet Gynecol 2007;109:419-433.

$\checkmark 10$ Franks PW, Hanson RL, Knowler WC et al. Childhood obesity, other cardiovascular risk factors, and premature death. N Engl J Med. 2010;362:485-493.

-11 Freedman DS, Mei Z, Srinivasan SR, Berenson GS, Dietz WH: Cardiovascular risk factors and excess adiposity among overweight children and adolescents: the Bogalusa Heart Study. J Pediatr. 2007;150: 12-17.e2

12 Trasande L, Chatterjee S: The impact of obesity on health service utilization and costs in childhood. Obesity 2009;17:1749-1754.

13 Cnattingius S, Villamor E, Lagerros YT, Wikstrom A-K, Granath F: High birth weight and obesity - a vicious circle across generations. Int J Obes 2011; doi:10.1038/ijo.2011.248.

-14 Whitaker KL, Jarvis MJ, Beeken RJ, Boniface D, Wardle J: Comparing maternal and paternal intergenerational transmission of obesity risk in a large population-based sample. Am J Clin Nutr 2010;91:1560-1567.

15 Sturm R: Increases in morbid obesity in the USA: 2000-2005. Public Health 2007;121:492-496.

16 Neovius M, Teixeria-Pinto A, Rasmussen F: Shift in the composition of obesity in young adult men in Sweden over a third of a century. Int J Obes 2008;32:832-836.

17 Howard NJ, Taylor AW, Gill TK, Chittleborough CR: Severe obesity: investigating the socio-demographics within the extremes of body mass index. Obes Res Clin Pract 2009;2: 51-59.

18 The National Obesity Observatory (NOO). The Epidemiology of Morbid Obesity. www.noo.org.uk/NOO_ about_obesity/Morbid_obesity (last accessed December 6, 2011).

19 De Onis M, Blossner M, Borghi. Global prevalence and trends of overweight and obesity among preschool children. Am J Clin Nutr 2010;92:1257-1264.

20 Wang YC, Gortmaker SL, Taveras EM: Trends and racial/ethnic disparities in severe obesity among US children and adolescents, 1976-2006. Int J Pediatr Obes 2011;6:12-20.

21 Kim SY, Dietz PM, England L, Borrow B, Callaghan WM: Trends in pre-pregnancy obesity in nine states, 1993-2003. Obesity 2007;15:986-993.

22 Wilson C, Gilliland S, Moore K, Acton K: The epidemic of extreme obesity among American Indian and Alaska Native adults with diabetes. Prev Chronic Dis 2007;4:A06.

23 Catalano PM, Farrell K, Thomas A, Huston-Presley L, Mencin P, Hauguel de Mouzon S, Amini SB: Perinatal risk factors for childhood obesity and metabolic dysregulation. Am J Clin Nutr 2009;90:1303-1313.

24 Whitaker RC: Predicting preschooler obesity at birth: the role of maternal obesity in early pregnancy. Pediatrics 2004;114:e29-e36.

25 Whitaker RC, Wright JA, Pepe MS, Seidel KD, Dietz WH: Predicting obesity in young adulthood from childhood and parental obesity. N Engl J Med. 1997;337:869-873.

26 Boney CM, Verma A, Tucker R, Vohr BR: Metabolic syndrome in childhood: association with birth weight, maternal obesity, and gestational diabetes mellitus. Pediatrics 2005;115:e290-e296. 
Dabelea D, Crume T: Maternal environment and the transgenerational cycle of obesity and diabetes. Diabetes 2011;60:1849-1855.

28 Levin BE: The obesity epidemic: metabolic imprinting on genetically susceptible neural circuits. Obes Res 2000;8:342-347.

29 Levin BE, Govek E: Gestational obesity accentuates obesity in obesity-prone progeny. Am J Physiol 1998; 275:R1374-1379.

-30 Sullivan EL, Smith MS, Grove KL: Perinatal exposure to high-fat diet programs energy balance, metabolism and behavior in adulthood. Neuroendocrinology 2011;93:1-8.

31 Davies GA, Maxwell C, McLeod L, et al: Obesity in pregnancy. J Obstet Gynaecol Can 2010;32:165-173.

32 Duchovny N, Baker C: How Does Obesity in Adults Affect Spending on Health Care? Congressional Budget Office Economic and Budget Issue Brief. September 8, 2010. Available at www.cbo.gov/doc. cfm?index=11810ઐzzz=41228 (last accessed January 23, 2011).

33 Office of Health Economics (OHE): Shedding the Pounds: Obesity Management, NICE Guidance and Bariatric Surgery in England. November 2010. Office of Health Economics 12 Whitehall, London SW1A2DY. Available at www.ohe.org (last accessed November 12, 2011).

-34 Durden ED, Dan Huse MA, Ben-Joseph R, Chu BC: Economic costs of obesity to self-insured employers. J Occup Environ Med 2008;50:991-997.

-35 Finkelstein EA, DiBonaventura MD, Burgess SM, Hale BC: The costs of obesity in the workplace. J Occup Environ Med 2010;52:971-976.

-36 Trasande L Lee M, Liu Y, Weitzman M, Savitz D: Incremental charges, costs, and length of stay associated with obesity as a secondary diagnosis among pregnant women. Med Care 2009;47:1046-1052.

37 Kral JG: Psychosurgery for obesity. Obes Facts 2009;2:339-341.

38 Kral JG: Selection of patients for anti-obesity surgery. Int J Obes 2001;25(suppl 1):S107-S112.

39 Kral JG: Surgery for obesity. Clin Perspect Gastroenterol 2001;4:298-305.

40 Kral JG, Kissileff HR: Surgical approaches to the treatment of obesity. Ann Behav Med 1987;9:15-19.

41 le Roux CW, Bueter M, Theis N Werling M, Ashrafian H, Löwenstein C, Athanasiou T, Bloom SR, Spector AC, Olbers T, Lutz TA: Gastric bypass reduces fat intake and preference. Am J Physiol Regul Integr Comp Physiol 2011;301:R1057-1066.

-42 Longitudinal Assessment of Bariatric Surgery (LABS) Consortium, Flum DR, Belle SH, King WC, et al: Perioperative safety in the longitudinal assessment of bariatric surgery. N Engl J Med 2009;361:445-454.

43 Kral JG, Dixon JB, Horber FF, Rossner S, Stiles S, Torgerson JS, Sugerman HJ: Flaws in methods of evidencebased medicine may adversely affect public health directives. Surgery 2005;137:279-284.

44 Sugerman HJ, Kral JG: Evidence-based medicine reports on obesity surgery: a critique. Int J Obes 2005;29: 735-745.

-45 Kahn HS: The lipid accumulation product performs better than the body mass index for recognizing cardiovascular risk: a population-based comparison. BMC Cardiovasc Disord 2005;5:26.

46 Padwal RS, Pajewski NM, Allison DB, Sharma AM: Using the Edmonton obesity staging system to predict mortality in a population-representative cohort of people with overweight and obesity. CMAJ 2011 183:E1059-1066.

-47 Elder KA, Wolfe BM: Bariatric surgery: a review of procedures and outcomes. Gastroenterology 2007;132: 2253-2271.

48 Adams TD, Pendleton RC, Strong MB, et al: Health outcomes of gastric bypass patients compared to nonsurgical, nonintervened severely obese. Obesity 2010;18:121-130.

-49 Adams TD, Stroup AM, Gress RE et al: Cancer incidence and mortality after gastric bypass surgery. Obesity (Silver Spring) 2009;17:796-802.

-50 Sjöström L, Gummesson A, Sjöström CD, et al: Effects of bariatric surgery on cancer incidence in obese patients in Sweden (Swedish Obese Subjects Study): a prospective, controlled intervention trial. Lancet Oncol. 2009;10:653-662

-51 Sjöström L, Peltonen M, Jacobson P, et al: Bariatric surgery and long-term cardiovascular events. JAMA 2012;307:56-65.

52 Sjöström L, Narbro K, Sjöström CD, et al: Effects of bariatric surgery on mortality in Swedish obese subjects. N Engl J Med 2007;357:741-752.

-53 Adams TD, Gress RE, Smith SC, Halverson RC, Simper SC, Rosamond WD, Lamonte MJ, Stroup AM, Hunt SC: Long-term mortality after gastric bypass surgery. N Engl J Med. 2007;357:753-761.

54 Maggard MA, Yermilov I, Li Z, Maglione M, Newberry S, Suttorp M, Hilton L, Santry HP, Morton JM, Livingston EH, Shekelle PG: Pregnancy and fertility following bariatric surgery : a systematic review. JAMA 2008;300: 2286-2296.

-55 Dixon JB, Dixon ME, O’Brien PE: Birth outcomes in obese women after laparoscopic adjustable gastric banding. Obstet Gynecol.2005;106:965-972.

56 Kral JG, Biron S, Simard S, Hould FS, Lebel S, Marceau S, Marceau P: Large maternal weight loss from obesity surgery prevents transmission of obesity to children followed 2 - 18 years. Pediatrics 2006;118(6):e1644e1649.

57 Smith J, Cianflone K, Biron S, Hould FS, Lebel S, Marceau S, Lescelleur O, Biertho L, Simard S, Kral JG, Marceau P: Effects of maternal surgical weight loss in mothers on intergenerational transmission of obesity. J Clin Endocrin Metab $2009 ; 94: 4275-4283$. 
Kral et al.: Severe Obesity: The Neglected Epidemic

58 born to mothers before and after surgically induced weight loss. Surg Obes Relat Dis 2011; DOI: 10.1016/j. soard.2011.09.016.

59 Sheiner E, Edri A, Balaban E, Levi I, Aricha-Tamir B: Pregnancy outcome of patients who conceive during or after the first year following bariatric surgery. Am J Obstet Gynecol 2011;204:50.e1-e6.

$>60$ Wax JR, Cartin A, Wolff R, Lepich S, Pinette MG, Blackstone J: Pregnancy following gastric bypass for morbid obesity: effect of surgery-to-conception interval on maternal and neonatal outcomes. Obes Surg 2008;18: 1517-1521.

$>61$ Doyle SL, Lysaght J, Reynolds JV: Obesity and post-operative complications in patients undergoing nonbariatric surgery. Obes Rev 2010;11:875-886.

-62 Kral JG, Otterbeck P, Touza MG: Preventing and treating the accelerated ageing of obesity. Maturitas 2010; 66:223-230.

63 DeMaria EJ, Murr M, Byrne TK, Blackstone R, Grant JP, Budak A, Wolfe L: Validation of the obesity surgery mortality risk score in a multicenter study proves it stratifies mortality risk in patients undergoing gastric bypass for morbid obesity. Ann Surg. 2007;246:578-582.

64 Hezelgrave NL, Oteng-Ntim E: Pregnancy after bariatric surgery: a review. J Obes 2011;doi:10.1155/2011/501939.

-65 Cools M, Duval EL, Jespers A: Adverse neonatal outcome after maternal biliopancreatic diversion operation: report of nine cases. Eur J Pediatr 2006;165:199-202.

66 Eerdekens A, Debeer A, Van Hoey G, et al: Maternal bariatric surgery: adverse outcomes in neonates. Eur J Pediatr 2010;169:191-196.

67 Chang S-H, Stoll CRT, Colditz GA: Cost-effectiveness of bariatric surgery: should it be universally available? Maturitas 2011;68:230-238.

68 deKeyser N, Josefsson A, Monfils WG, Claesson IM, Carlsson P, Sydsjö A, Sydsjö G: Total cost comparison of standard antenatal care to a weight gain restriction program for obese pregnant women. Public Health. 2011;125:311-317.

-69 Sugerman HJ, Londrey GL, Kellum JM, et al: Weight loss with vertical banded gastroplasty and Roux-Y gastric bypass for morbid obesity with selective versus random assignment. Am J Surg 1989;157:93-102.

-70 Martin LF, Tan TL, Holmes PA Becker DA, Horn J, Mann LD, Bixler EO: reoperative insurance status influences postoperative complication rates for gastric bypass. Am J Surg 1991;161:625-634.

71 Alexander JW, Goodman HR, Hawver LRM, James L: The impact of Medicaid status on outcome after gastric bypass. Obes Surg 2008;18:1241-1245.

72 D'Angelo D, Williams L, Morrow B, Cox S. Harris N, Harrison L, Posner SF, Hood JR, Zapata L: Preconception and interconception health status of women who recently gave birth to a live-born infant - Pregnancy Risk Assessment Monitoring System (PRAMS), United Stated, 26 reporting areas, 2004. MMWR Surveillance Summaries 2007;56(SS10):1-35.

-73 Martin M, Beekley A, Kjorstad R, Sebesta J: Socioeconomic disparities in eligibility and access to bariatric surgery: a national population-based analysis. Surg Obes Relat Dis 2010;6:8-15.

74 Halloran K, Padwal RS, Johnson-Stoklossa C, Sharma AM, Birch DW: Income status and approval for bariatric surgery in a publicly funded regional obesity program. Obes Surg 2011:21:373-378.

75 Ogden CL, Carroll MD: Prevalence of Overweight, Obesity, and Extreme Obesity among Adults: United States, Trends 1960-1962 through 2007-2008. (Table 1). NCHS Health E-Stats June 2010. Available at www. cdc.gov/nchs/data/hestat/obesity_adult_07_08/obesity_adult_07_08.htm (last accessed April 11, 2012).

76 National Institutes of Health (NIH): Gastrointestinal Surgery for Severe Obesity. NIH Consensus Statement Online 1991 Mar 25-27;9(1):1-20. Available at http://consensus.nih.gov/1991/1991gisurgeryobesity084html.htm (last accessed January 24, 2012).

77 National Institutes of Health. NHLBI and NAASO. The Practical Guide: Identification, Evaluation, and Treatment of Overweight and Obesity in Adults. NIH Publication Number 00-4084, October 2000. Available at www.nhlbi.nih.gov/guidelines/obesity/prctgd_c.pdf(last accessed January 24, 2012).

78 Centers for Medicare \& Medicaid Services: Decision Memo for Bariatric Surgery for the Treatment of Morbid Obesity (CAG-00250R). 2006. Available at www.cms.gov (last accessed February 8, 2011).

79 Centers for Medicare \& Medicaid Services: Decision Memo for Surgery for Diabetes. (CAG-00497N), February 12, 2009. Available at www.cms.gov (last accessed February 8, 2011).

80 Ferguson C, Leonard J, Kaufman N,Younger K, David S, Hertzog C, Sheer J, Breese E, Plavchak B, Stevens C, Stoto A: Medicaid fee-for-service treatment of obesity interventions: 50 state \& District of Columbia survey. The George Washington University Department of Health Policy. Available at www.stopobesityalliance.org (last accessed July 20, 2011).

81 Ruhm CJ: Current and future prevalence of obesity and severe obesity in the United States. Forum Health Economics Policy 2007;10:1-26.

-82 Guh DP, Zhang W, Bansback N, Amarsi Z, Birmingtham CL, Anis AH: The incidence of co-morbidities related to obesity and overweight: A systematic review and meta-analysis. BMC Public Health 2009;9:88.

-83 Kral JG: ABC of obesity. Management: part III - surgery. BMJ 2006;333:900-903. 